\title{
Cambios en la historiografía académica en Argentina (2001-2015)*
}

\author{
Changes in Argentina's academic History (2001-2015)
}

\author{
Ernesto Bohoslavsky \\ ebohosla@ungs.edu.ar \\ Professor \\ CONICET e Universidad Nacional de General Sarmiento \\ J. M. Gutiérrez 1150 (1613), Los Polvorines \\ Província de Buenos Aires \\ Argentina
}

\section{Resumen}

Este artículo discute algunas de las modificaciones vividas por la historiografía argentina a inicios del siglo XXI. Asimismo, también se ofrecen indicios acerca de cuáles han sido los temas que han generado mayor interés en los últimos años en la historiografía académica, una disciplina que ha vivido un impactante proceso de expansión y consolidación. Se intenta mostrar que uno de los efectos de la crisis económica y política de 2001 fue una intensificación de la preocupación por la manera de difundir los saberes sobre la historia nacional, sobre todo la referida a la última dictadura. Algunas de las discusiones y las prácticas de divulgación han puesto en debate los problemas de la normalización profesional ocurrida en los años ochenta y noventa.

\section{Palabras-clave}

Argentina; Historiografia; Política.

\section{Abstract}

This article discusses the changes lived by Argentina's academic historiography at the beginning of the 21st century. Furthermore, here is offered some information about which have been the most attractive topics in scholar history, which definitively became an expanding and consolidated social science. It's intended to show that one of 2001 economical and political crisis' impact was the enlargement of discussions on how to spread historical scholar knowledge, mainly the one referred to the last dictatorship. Some of these debates and diffusion practices have stimulated historians to re-think the problems that professional "standardization" has generated in the eighties and nineties.

\section{Keywords}

Argentina; Historiography; Politics.

Recibido el: 20/7/2015

Aceptado el: 10/1/2016

\footnotetext{
* Este texto fue producido en el marco del Proyecto de Investigación Científico-Técnico 2013/1160 "Desafíos teóricos, historiográficos y didácticos del abordaje del pasado reciente en Argentina", financiado por el Fondo para la Investigación Científica y Tecnológica de la Agencia Nacional de Promoción Científica y Tecnológica, República Argentina.
} 
Si hay algo peor que hacer un examen de conciencia demasiado pronto es hacerlo demasiado tarde (ROTH 2000, p. 99).

Este artículo tiene la intención de mostrar algunas de las modificaciones suscitadas en el campo de la historiografía académica argentina en los últimos quince años. ${ }^{1}$ En ese período se ha consolidado un campo disciplinario muy diversificado y heterogéneo, en diálogo (subordinado) con las metrópolis académicas y sus agendas de investigación. Este campo ha vivido una expansión que se expresa en la ampliación del número de proyectos de investigación, investigadores, becarios, programas de posgrado y eventos académicos vinculados a la disciplina. Ese campo está "normalizado" según señala la bibliografía sobre el particular (PAGANO 2010): sobre el significado del término hay poca discusión, pero sí la hay en torno a las valoraciones sobre ese proceso, así como sobre la existencia, la necesidad o la viabilidad de mecanismos que filtren, limen o sobrepasen esa normalidad. Por normalización se entiende el proceso por el cual la historiografía argentina adoptó patrones internacionales de funcionamiento regular tales como un "abordaje metodológico riguroso, el uso variado de documentos, la explicitación del aparato erudito en los textos y una búsqueda de distancia crítica con el objeto de estudio" (DI MEGLIO 2011). La contracara de este proceso -a veces agriamente reconocida, otras veces entusiastamente asumida- es la despolitización de la práctica historiográfica, expresada en la convicción de que un ajustado estudio del pasado en poco o en nada colaborará en la comprensión y sobre todo posible intervención en la vida social contemporánea. Ese escepticismo fundacional sobre la capacidad para "formar las almas" descansa en razones que acertadamente ha indicado Alejandro Eujanian:

primero porque no es nuestro objetivo, segundo porque no nos pondríamos de acuerdo, tercero porque [...] aquello que se considera historia profesional o académica todavía puede estar sujeto a discusión. Por último, [porque] dependerá menos de nosotros que de la decisión política de apropiarse de nuestra producción como un insumo para hacer con él otra cosa (EUJANIAN 2011, p. 179).

Podría especularse que frente a ese divorcio entre pasado y presente generado por una despolitización vigilada del campo historiográfico argentino, en los últimos años han sido cultivados espacios profesionales en los cuales se despliegan otras estrategias de difusión y transmisión del pasado: los museos, la reflexión sobre la enseñanza y la divulgación audiovisual y bibliográfica son

\footnotetext{
${ }^{1}$ Agradezco a Sandra Fernández la información sobre el funcionamiento de las Jornadas Interescuelas y Departamentos de Historia y a Mónica Marquina los presupuestos nacionales de la última década. Asimismo, hago llegar mi reconocimiento a Guadalupe Ballester, Pablo Buchbinder, Maximiliano Catoira, Jorge Cernadas, María Paula González, Alejandro Eujanian y Daniel Lvovich por sus sugerencias y lecturas. Las versiones preliminares presentadas en la Universidade Estadual Paulista (Assis, Brasil), la Universidad del Centro de la Provincia de Buenos Aires (Tandil, Argentina) y la Universidad Autónoma de Baja California (Mexicali, México) fueron enriquecidas por los comentarios de los asistentes. Como es tradición, a todos ellos eximo de los errores y problemas que este texto contiene.
} 
algunos de esos ámbitos. Mientras que la normalización de la disciplina estimuló y premió la publicación en revistas especializadas e internacionalmente indexadas de artículos con un nivel de refinamiento metodológico y conceptual que resultan de escaso interés para el grueso de la población, en los últimos quince años se han ido presentando o desplegando propuestas en sentidos divergentes. Este artículo intenta mostrar que el desarrollo de esas actividades académicas y paraacadémicas ha ido de la mano de un diálogo con algunas políticas de ciencia y tecnología y con políticas de memoria ensayadas en los últimos años en Argentina. Para ello se ha organizado este texto en cuatro secciones: la primera de ellas da cuenta del proceso de expansión de la historiografía argentina en los últimos quince años gracias a la ampliación del gasto público y la consolidación disciplinar. La segunda sección ilustra sobre el particular crecimiento que tuvieron los estudios dedicados a la historia reciente argentina, en vínculo con el campo de la memoria y de la enseñanza. La tercera sección se concentra en el impacto que tuvo la crisis de 2001 sobre las prácticas historiográficas, específicamente en materia de desarrollo de estrategias de divulgación por fuera de las opciones consideradas legítimas o centrales en el paradigma normalizador. La cuarta sección intenta mostrar cómo el proceso de expansión de la historiografía se entroncó con otros dos que fueron convergentes: una política pública destinada a fomentar rasgos identitarios de raíz histórica y por otro lado, con la politización de un amplio sector del público de las librerías, que expresó mayor interés por encontrar claves explicativas de la realidad en el pasado nacional. Finalmente, en las conclusiones

104 se ofrecen algunas ideas sobre las prácticas historiográficas actuales.

\section{La historiografía académica: expansión, consolidación y especialización}

Los gobiernos kirchneristas (2003-2015) ampliaron sustancialmente el presupuesto en las áreas educativas y de ciencia y tecnología. La decisión de llevar la inversión educativa anual al 6\% del PBI, expresada en la Ley de Financiamiento Educativo, constituyó el marco general de tal incremento. La creación en el año 2007 del Ministerio de Ciencia y Tecnología fue en igual sentido. El impacto financiero sobre las universidades y las instituciones promotoras de la investigación se dejó sentir muy fuertemente en los últimos años, multiplicando el número de proyectos, de becarios doctorales y posdoctorales y de investigadores. Lo que han mostrado algunos análisis de la política universitaria de los gobiernos Kirchner es la ausencia de una clara línea programática (CHIROLEU; IAZZETTA 2009), pero en lo que se refiere a los presupuestos, se observa un notorio crecimiento, que debe ser analizado con cierto detenimiento. Como mostró Mónica Marquina (2012), las universidades nacionales quintuplicaron su presupuesto entre 2003 y 2010, pero lo hicieron a) en un contexto inflacionario, sobre todo desde 2006, que hizo que en realidad el efecto fuera de duplicación o cuadruplicación según el índice de precios que se use; b) sin mejorar demasiado su participación en el total del presupuesto nacional (entre 3\% y 3,8\%). Lejos de ser suficiente, ese incremento de los presupuestos, así como la continuidad de los programas de ampliación de la dedicación laboral de los docentes y de reincorporación de investigadores 
argentinos residentes en el exterior y los numerosos proyectos y becarios financiados por la Agencia Nacional de Promoción Científica y Tecnológica y el CONICET, contribuyeron a un aumento de las oportunidades del desarrollo de investigaciones en diversas disciplinas, entre ellas la historiografía. Todas esas tendencias permitieron que explotaran temas y preocupaciones que hasta entonces habían estado más esbozados que realmente desarrollados. Entre otras cosas, alentó la internacionalización de algunas actividades académicas a través de la participación en eventos científicos en el extranjero, financiación de intercambios de docentes e investigadores y de proyectos de investigación con universidades del exterior.

Uno de los puntos que reflejan claramente la expansión de la actividad historiográfica tiene que ver con las Jornadas Interescuelas y Departamentos de Historia. Se trata del evento académico más relevante del campo profesional, organizado cada dos años por las escuelas y departamentos de historia de universidades públicas nacionales. Si en las jornadas de 1999 hubo poco más de medio centenar de mesas temáticas, diez años después había sido aceptado casi el doble de mesas. En efecto, una recorrida muy rápida sobre el particular da cuenta de la evolución del volumen de participantes en estas jornadas:

\begin{tabular}{lccccccccc}
\hline & 1997 & 1999 & 2003 & 2005 & 2009 & 2011 & 2013 & 2015 \\
\hline Mesas temáticas & 37 & 56 & 67 & 87 & 95 & 99 & 128 & 114 \\
Ponencias aceptadas & 276 & s.d. & 766 & 900 & s.d. & 1100 & 2001 & s.d. & 105 \\
\hline
\end{tabular}

Este nivel de crecimiento y de consolidación puede rastrearse en cualquier otro evento del campo que se realice con regularidad: las Jornadas de Historia Económica (con sede rotativa), las jornadas "Espacio Memoria e identidad" (con sede en la Universidad Nacional de Rosario) o las Jornadas de Trabajo sobre Historia Reciente (también con sede rotativa).

Un asunto bien distinto es tratar de discernir cuáles fueron los temas y cuestiones que más se discutieron en esas jornadas. Es que en la actualidad el campo académico de la historiografía tiene tal envergadura y complejidad que difícilmente se pueda observar, como hasta mediados de la década de 1990, quiénes eran los historiadores que eran "dueños" de un tema. Esos patronazgos son ahora discutidos, y la aparición de nuevas universidades en los últimos quince años permite adivinar que ese proceso de desvanecimiento de autoridades consuetudinarias en el campo, se irá profundizando aún más. Por patronazgo me refiero a la constitución de redes jerarquizadas, piramidales y endogámicas que ofrecen recursos simbólicos y materiales para sus integrantes, a la vez que celan por la posibilidad de que otros grupos de colegas produzcan análisis e investigaciones alternativas y competitivas, sobre los mismos temas. Lo que se percibe cada vez con mayor notoriedad es la creciente diversificación y especialización que dominan a la práctica historiográfica profesional. La multiplicidad de grupos, de temas, de eventos y de publicaciones dificulta 
cualquier visión no ya de conjunto de la historiografía profesional, sino de los diversos sub-campos en que se encuentra dividida El panorama no es nuevo. Hace una docena de años un balance de la historiografía argentina destacaba que ésta tenía sintonía con otros campos académicos historiografías nacionales en lo que se refería a

la falta de un paradigma dominante, perceptible en la multiplicidad de aproximaciones, tendencias, métodos y horizontes teóricos utilizados en las investigaciones presentadas [...] fuerte internacionalización, perceptible en las redes y los intercambios académicos (RODRÍGUEZ 2002-2003, p. 293).

En efecto, no se trata de un problema argentino ni mucho menos. En términos irónicos un destacado colega italiano se refería a la supuesta "crisis" de la disciplina histórica en Europa:

Estoy hablando del diluvio de libros, artículos, revistas, conferencias de historia que se abaten cada año sobre el público. No me parece que ésta sea aquella gran crisis de la disciplina (MASTROGREGORI 2012 , p. 1). ${ }^{2}$

Se trata, entonces, de un vigor más renovado que original. La noticia no está en cómo se investiga sino en cuánto se investiga ¿Hay algo dónde reside la novedad de la historiografía argentina? ¿En el que se investiga? ¿Son distintos los temas actuales de aquellos que dominaban la escena en 2001? La respuesta parece ser que no, salvo por unas pocas innovaciones. Ello guarda relación con el hecho de que la agenda de investigación parece responder principal, cuando no exclusivamente, a una lógica interna de las (sub)disciplinas, que a su vez están (asimétricamente) vinculadas a una dinámica metropolitana de desarrollo de las ciencias humanas y sociales. Uno de los puntos que aparece como innovador, y además como evidente herencia de la crisis de 2001 y 2002, es el reverdecido interés por el accionar político de los sujetos subalternos. Vale la pena hacer notar algunas de las diferencias de estas perspectivas respecto de la historia de los trabajadores o la historia del movimiento obrero, tendencias que en los años ochenta y noventa sufrieron una fuerte caída del interés en toda América latina (MALERBA 2010). Las preocupaciones historiográficas de la década del 2000 no pasan tanto por la vida de los sindicatos ni el peso político de los trabajadores sino por el análisis de otros actores cuya principal pertenencia no era -o no era siempre, o no era la principal- la pertenencia de clase, aun cuando un estudio de estratificación social nos permitiría clasificarlos objetivamente como trabajadores. Así, los trabajos de Gabriel Di Meglio (2007) sobre el "bajo pueblo" en la Revolución de Mayo de 1810, el de Raúl Fradkin (2008) sobre la historia popular de la primera mitad del siglo XIX, el de Ricardo Salvatore (2003) sobre la agencia plebeya en tiempos rosistas, el de Adriana Kindgard 
sobre las prácticas políticas de indígenas jujeños bajo el peronismo (2004), son esfuerzos historiográficos que, sin haber nacido estrictamente en 2001, testimoniaron mejor que otros cómo las preguntas del presente formateaban a aquellas orientadas al pasado.

Se podría especular que el ingreso en la historiografía de la conflictividad plebeya fue el resultado de varios factores convergentes. En primer lugar, la recurrente presencia desde finales de los años noventa de la agencia política subalterna en los medios y la vida cotidiana en un contexto de rápida y masiva caída de los indicadores socio-económicos (KESSLER et al. 2010). Es como si las escenas de diciembre de 2001, la reiteración de los piquetes en calles y rutas, hubiesen convocado a los historiadores a percibir una novedad que valía la pena rastrear en el pasado. En segundo lugar, la legitimidad que recibieron selectivamente, también hay que decirlo- algunas de esas expresiones políticas a partir de la asunción como presidente de Néstor Kirchner, en mayo de 2003. La decisión de seducir, cooptar y/o aceptar a algunos grupos de trabajadores, precarizados, desempleados, piqueteros, etc., llevó a que la protesta social fuera parte de la vida diaria de millones de argentinos, que la veían en la televisión, en las calles y las rutas, en las escuelas, hospitales, universidades y fábricas entre algunas de las instituciones que albergaron conflictos (SVAMPA; PEREYRA 2009). En tercer lugar, por la escucha cada vez más atenta que algunos historiadores (GIORDANO 1996; MAYO 1997) prestaron a los Subaltern Studies de la India, que invitaban a percibir los conflictos sociales con categorías y herramientas que incluían -pero también escapaban- a las más tradicionales metodologías con las que se estudiaban los choques de clases de sociedades urbanas (GUHA 2002; RIVERA CUSICANQUI; BARRAGÁN 2002).

Pero probablemente la gran novedad historiográfica argentina en lo que va del siglo XXI no es el estudio de las condiciones de subalternidad sino la imantación que ha producido la historia del pasado inmediato.

\section{Historia reciente: política y memoria}

Al finalizar las VII Jornadas Interescuelas y Departamentos de Historia en 1999, se dirigió al público la directora del Departamento de Historia de la Universidad Nacional del Comahue, la institución organizadora. En esa ocasión Gladys Varela señalaba que

En estas jornadas, hemos observado, cómo un número importante de colegas jóvenes, empiezan a preocuparse sobre la historia del pasado cercano, particularmente del argentino, que tanto ha marcado a nuestra sociedad, logrando romper el bloqueo que el análisis de ciertas temáticas producía a nuestra generación (VARELA 2000, p. 257).

Si en 1999 ya se avizoraba la aparición de "colegas jóvenes" que se preocupaban por el pasado cercano, lo que hoy tenemos es la profundización de ese fenómeno a niveles imposibles de imaginar sobre el filo del siglo pasado. En efecto, el campo de la llamada "historia reciente" es el que ha tenido un verdadero boom en la última década. Se han multiplicado las publicaciones, 
los eventos, los sitios web y los espacios de formación destinados a la difusión y producción de conocimientos sobre el pasado cercano. ${ }^{3}$ Por ese pasado se entiende, en líneas generales, al período posterior a 1955, aunque, por la propia naturaleza polémica del campo (FRANCO; LEVIN 2007), esos límites no son nada rígidos. Es cierto que se trata de un fenómeno de alcance global, que ha contribuido a entronizar a la memoria como un objeto de análisis primordial, cuando no exclusivo (HUYSSEN 2002).

La gran producción bibliográfica sobre historia reciente nace en parte como respuesta a las indagaciones periodísticas producidas en la década de 1990 y también a la de corte testimonial, que aspiraba a dar a conocer los detalles de los mecanismos de represión, así como de la subjetividad revolucionaria desarrollada en el período anterior a la dictadura: pienso aquí en un libro como Recuerdos de la muerte (BONASSO 1984). Al final del siglo XX un historiador podía decir que en los quince años anteriores "ha aparecido una abundante y despareja producción sobre los '70 desde la que se han formulado distintas preguntas al pasado" (DE AMEZOLA 1999, p. 142). Ese crecimiento ha sido mucho mayor desde entonces. El estudio de la historia reciente ha permitido identificar a un conjunto de actores que hasta hace diez años apenas tenían lugar en el registro historiográfico: los exiliados (FRANCO 2008; JENSEN 2010), las mujeres embarcadas en las actividades guerrilleras en las décadas de 1960 y 1970 (ANDUJAR et al. 2011) o los abogados radicalizados (CHAMA 2006), entre otros.

Este campo de estudios se constituyó y consolidó, a diferencia de otros, 108 con tres rasgos particulares que quisiera detallar y cuya historicidad no responde exclusivamente a la dinámica historiográfica. Como resultado de la combinación de esos tres aspectos, abajo indicados, hay en marcha una difícil -e improbable- separación entre los que se dedican a analizar testimonios por un lado, los que intentan reconstruir un proceso socio-histórico pasado y quienes estudian cómo se enseñan o se podrían enseñar estas cuestiones en las aulas. Esos tres rasgos son:

a) diálogo con el mandato (y el problema de) la transmisión en sede escolar de esas memorias tomadas como ejemplares. González (2014, p. 59-75) señaló el despliegue de políticas de memoria en ámbitos educativos incluso poco antes de los años noventa- que se expresó en la implantación de nuevas efemérides como el 24 de marzo (día de aniversario del golpe de Estado de 1976) y el 16 de septiembre (aniversario del secuestro de un grupo de estudiantes secundarios en La Plata en 1976) y en la inclusión de contenidos sobre las décadas de 1970 y 1980 con una matriz crítica. Si bien tales novedades en el ámbito escolar no fueron consecuencia de un desarrollo historiográfico previo, los avances de la disciplina histórica fueron incorporándose posteriormente a las sucesivas modificaciones curriculares. Pero hasta no hace mucho fueron otras 
ciencias sociales y las organizaciones defensoras de derechos humanos las que impulsaron y dotaron de contenido a los diseños curriculares y las efemérides (GONZÁLEZ 2014, p. 74-76).

b) recurrencia de la comparación con otras experiencias latinoamericanas. En efecto, el interés por los procesos dictatoriales sudamericanos es una marca registrada de quienes se dedican al estudio del tiempo reciente (BERGERO; REATI 1997; GROPPO; FLIER 2001; BOHOSLAVSKY et al. 2010b), incluyendo en algunos casos la comparación con España (AGUILA; ALONSO 2013; CHÁVES PALACIOS 2010).

c) superposición con los estudios sobre la memoria de los pasados traumáticos. La fuerte producción del Núcleo de estudios sobre memoria del Instituto del Desarrollo Económico y Social (Buenos Aires), la maestría en Historia y Memoria de la Universidad Nacional de La Plata (junto a su revista Aletheia) y las actividades promocionadas por la Comisión Provincial por la Memoria, con sede en La Plata, han sido probablemente los grandes animadores de un debate que ya parece imposible de reseñar por la cantidad de participantes (CHAMA; SORGENTINI 2010). Es que el estudio de las memorias de los pasados traumáticos es prácticamente un campo científico con autonomía (CARNOVALE et al. 2006; JELIN; KAUFMAN 2006; JELIN; LONGONI 2005), que se evidencia en el notorio crecimiento de la historia oral como sub-campo. ${ }^{4}$ La creación de la Asociación Argentina de historia oral, la muy numerosa presencia de interesados en practicar y reflexionar sobre la historia oral, las revistas Testimonios y Voces recobradas parecen mostrar la amplitud y vitalidad de un campo, lo cual es también parte de un fenómeno mayor, de alcance occidental. Ello le ha permitido a la historia oral dejar de ser una rama "subversiva" y desacartonada de la disciplina histórica y pasar a ser "respetable" y estar en franco proceso de institucionalización y reconocimiento académico (FIELD 2009).

Uno de los problemas que en los últimos años fue asumido con más valentía que certezas metodológicas, tiene que ver con el problema (político) de cómo generó y obtuvo consenso la dictadura en la población (LVOVICH 2010). El otro punto interesante de este enfoque del pasado reciente es que dejaba de lado una premisa que las ciencias sociales y la historiografía habían asumido durante la transición a la democracia: la existencia de un enfrentamiento de larga data en la historia argentina entre autoritarismo y democracia (CHAMA; SORGENTINI 2010). Así, se ha postulado que después de 1983, en Argentina

los historiadores más relevantes del campo académico aspiraron a construir una narrativa nacional que dotara de sentido a la nueva experiencia. Contaron historias que apuntaban a la construcción de un país normal,

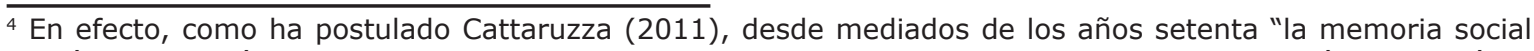
no sólo conquistó legitimidad como objeto de estudio entre los historiadores, sino que también se volvió un campo muy frecuentado". Eujanian (2011) ha ofrecido sólidos contra-argumentos contra la existencia de ese supuesto "boom" en Occidente.
} 
capitalista y democrático, contra el país deforme de los años anteriores. La normalización del país tuvo su correlato en la reconfiguración de la historia nacional: la lectura que se hacía entonces del pasado estaba atravesada por la clave del desarrollo de la democracia (VÉLIZ et al. 2010, p. 38).

El repudio y abandono de la llamada "teoría de los dos demonios" que suponía que el accionar guerrillero y su represión clandestina eran moral y legalmente equivalentes (FRANCO 2015) ha permitido reconstruir las particulares situaciones y contextos en que diversos actores recurrieron a prácticas autoritarias. Como señalan Chama y Sorgentini (2010), ese ejercicio ofreció una comprensión más amplia de los actores en su contexto, pero a cambio generó una fuerte tensión con la necesidad de mantener el rigor moral de la condena a sus actos. Por la naturaleza de los temas abordados, por el uso -posible o real- de los saberes académicos en aulas de las escuelas, por el vínculo con el sostenimiento de la memoria, la historia reciente presenta algunas confrontaciones -que no rupturas- con el paradigma de la normalidad historiográfica. La ampliación del número de practicantes de este campo especializado ha permitido poner en discusión algunos de los supuestos en los que se basaba el proceso de "reprofesionalización del campo historiográfico" argentino (PAGANO 2010) en las décadas de 1980 y 1990. Como en muchos otros aspectos, los cambios en la historiografía obedecían al impacto de fenómenos ajenos al campo, como fue la crisis de inicios del siglo XXI.

\section{1: el año que vivimos peligrosamente (y llegamos tarde)}

Los efectos de la convulsión social y política del 2001 en Argentina fueron múltiples. Entre otros, que aquí interesan, se cuentan el abandono de muchas de las pretensiones y auto-imágenes que habían sustentado la transición a la democracia en los primeros años ochenta. $Y$ en ese grupo de nociones se incluían también referencias acerca de la misión de los científicos, del vínculo entre intelectuales y política y entre universidad y desarrollo. Esas ideas se fueron abriendo paso en la medida en que

la confianza en el 'país normal' y en la democracia 'sin adjetivos' propia de la coyuntura alfonsinista -que de manera larvada funcionaba como soporte ideológico del campo historiográfico- se fue haciendo añicos (ADAMOVSKY 2011, p. 91).

Esa erosión de las convicciones que habían orientado al proceso de normalización se combinó con una inusitada demanda de saberes sobre el pasado, demanda montada en la convicción de que debía buscarse en ese tiempo pretérito alguna de las claves para entender lo que era diagnosticado como un "fracaso nacional", En efecto, pese a las expectativas en contrario, "la sociedad sí demandaba sentidos a la historia y los historiadores profesionales no estaban a la altura de esa demanda" (ADAMOVSKY 2011, p. 91). Todavía en pleno impacto de la crisis, Alejandro Cattaruzza (2002, p. 33) creía encontrar en este renovado interés por el poder explicativo del pasado, una "oportunidad 
para que los historiadores que creemos que nuestros procedimientos entrenan en el ejercicio del juicio crítico sobre la realidad volviéramos a actuar allí, en la sociedad; ése es un horizonte que nunca debimos haber abandonado".

El diagnóstico de muchos historiadores era que cuando la sociedad reclamó la provisión de herramientas intelectuales y culturales para comprender cómo había llegado al borde de la auto-disolución nacional, el campo historiográfico estaba políticamente inerte, incapaz de ofrecer nada salvo discursos crípticos y auto-centrados y que debían restablecerse puentes entre la historiografía profesional y el gran público. Por ello una de las herencias de la crisis de 2001 sobre la práctica historiográfica guarda relación con las estrategias usadas para la circulación del conocimiento. Así, emergió una preocupación intensa por el problema de la divulgación de los saberes académicos por fuera de las propias instituciones académicas. ¿Para quién se escribe?, ¿quién lo lee?, ¿qué se hace con esos conocimientos? Estas preguntas se instalaron con cierta recurrencia, y en algunos casos generaron posicionamientos muy críticos hacia las estrategias endogámicas de legitimación asumidas por los historiadores profesionales, que supuestamente le daban la espalda a problemas sociales relevantes. Es por ello que en la década del 2000 un grupo significativo de historiadores se preocupó de manera muy sincera, muy política (VELIZ et al. 2010) y muy productiva del problema de la difusión y la popularización de la ciencia, así como por los usos sociales de los saberes (CATTARUZZA 2010) y se encargó de la producción de materiales audiovisuales, ${ }^{5}$ de bibliografía para divulgación (BANDIERI 2005; BARRANCOS 2008; BRAGONI 2010; BUCHBINDER 2008; CATTARUZZA 2007; DEVOTO 2003; GOLDMAN 2009; MORENO 2009) y de manuales de uso escolar. Probablemente uno de los puntos en los que se evidencian esos puntos de contacto entre los historiadores profesionales y un mundo mayor, sea en la producción de libros de texto para la educación media. En esa interfaz entre educación, investigación y divulgación se producen turbulencias profesionales, académicas y de distribución del poder que sólo recientemente han venido a ser puestas en discusión (DE AMEZOLA 2008). En la década de 1990 numerosos historiadores profesionales intervinieron en la producción de manuales de historia que tienen por destinatarios a los profesores o los estudiantes de escuela media (por ejemplo, DE PRIVITELIO et al. 1998). A los interesados en estas cuestiones recomiendo la lectura del artículo de Mariana Lewkowicz y Martha Rodriguez incluido en este mismo dossier.

\footnotetext{
${ }_{5}^{5}$ Numerosas producciones audiovisuales se han venido ofreciendo por el canal estatal Encuentro desde su creación en 2007, cuya programación se centra en la difusión de la ciencia, la cultura y la historia. Al final del 2015 los programas dedicados a la difusión de historia nacional en Encuentro son "10 minutos de historia" Historia de un país. Argentina siglo XX", "Bio.ar", "Caudillos", "La asombrosa excursión de Zamba en el Cabildo" (un cómic que mixtura tiempos actuales con 1810, gracias a una animación) y "Mujeres. Lo personal es político". Todos esos materiales pueden ser descargados libremente en: http://descargas.encuentro.gov. ar/tema.php?tema id=4. Junto con ello hay ciclos dedicados a temas puntuales de historia como "Años decisivos", "Argentina y la gran guerra", "Asamblea 1813", "Bajo pueblo", "Batallas de la libertad", "Crónicas de archivo", "Ejército y política", "Escenas de la historia de un país", "Historia de la clase media argentina", "Historia de las clases populares", "Historia de los partidos políticos", "XIX: Los proyectos de nación", "Jesuitas en Córdoba", "Juventud y militancia", "La era de los caciques", "Los Valencia, serie animada", "Madres de la plaza", "Malvinas. La historia de la usurpación", "Padres de la plaza", "Pensar Malvinas", "Presidentes argentinos", "Pueblos originarios" y "Revoluciones", entre otros.
} 
Estas iniciativas testimonian también la existencia de un recambio generacional al interior del campo. Al poner el acento en el vínculo entre la ciencia histórica y la sociedad, se alejaban del que había sido el propósito inicial de la generación que lideró la reconstrucción disciplinaria en la década de 1980 y que lideró el proceso de "normalización" de las universidades durante el gobierno de Alfonsín. Esta generación consideró urgente apostar por la constitución científica de la disciplina, autonomizándola de las presiones ejercidas por las fuerzas sociales y políticas. Tanto la discusión sobre el agotamiento de la historiografía académica como proyecto "profesional" así como las impugnaciones más severas al ordenamiento despolitizante dentro del campo son anteriores a la crisis del 2001. Era un aspecto sobre el cual incluso algunos historiadores consagrados admitían ya a mediados de los años noventa que valía la pena debatir (Hora y Trímboli 1994). En igual sentido iba el Manifiesto de Octubre lanzado por un conjunto de estudiantes y graduados de la carrera de historia de la Facultad de Filosofía y Letras de la Universidad de Buenos Aires, pieza clave del campo académico argentino. Según denunciaban con fuerte potencia política en 1997, la situación que se vivía era de hartazgo respecto del modelo de historiador profesional, productor serial de papers: "nos invita a que medremos, a pulirnos en el aprendizaje de congraciar a los sucesivos referatos y evaluaciones para que el sueño de una carrera universitaria exitosa no se vea interrumpido" (TRÍMBOLI et al. 1997, p. 2). Una de las voces más lúcidas de la crítica a la generación de historiadores "normalizadores" -y también firmante del Manifiesto

112 de Octubre- planteó abiertamente la necesidad de abandonar el paradigma del distanciamiento del historiador profesional respecto de su sociedad y las tensiones políticas contemporáneas:

Nuestros interrogantes del presente orientan las preguntas que lanzamos
al pasado. Las respuestas que encontramos allí llevan la esperanza de
dotarnos de claves para mejorar nuestra vida actual [...] En ese interés
práctico por el pasado coincidimos (o deberíamos coincidir) tanto
historiadores como el vecino de a pie. Una conexión más estrecha entre
el historiador profesional y el gran público - con los recaudos que sean
necesarios- no conspira contra la buena historia: por el contrario, la
fortalece" (ADAMOVSKY 2011, p. 104).

La pregunta por la circulación de los saberes también provino de confrontar con el masivo éxito comercial obtenido por aquellos productos generados por intelectuales o comunicadores mediáticos, carentes de prestigio académico, pero llenos de lectores, oyentes y televidentes (LANATA 2002, 2004; PIGNA $2004,2005,2006,2008)$. La percepción de que los relatos sobre el pasado que más circulaban eran los provistos por estas figuras (RODRÍGUEZ 2010; SEMÁN et al 2009) también reforzó la auto-crítica de miembros del campo, por haber desdeñado durante mucho tiempo la divulgación de la ciencia y sobre todo por haberle sacado el cuerpo a la dimensión política de la historia, al punto de producir una "malla de escritura que sólo deja enunciar aquello que no tenga rasgo de pasión, de dramaticidad" (TRÍMBOLI et al. 1997, p. 4). Es interesante que el vínculo entre los historiadores profesionales y los amateurs 
o "prácticos" haya sido estudiado en otros puntos del planeta. Así, Malerba ha mostrado en esta misma revista que esos lazos no son necesariamente ríspidos en Estados Unidos y Australia, pero sí más complicados en Brasil (MALERBA 2014, p. 28-33).

\section{Política pública, público politizado y usos de pasado}

Es notorio el incremento en el consumo social de libros, películas y programas de radio y televisión dedicados a la historia argentina desde 2001. Ese revival de la historia viene de la mano de un resurgimiento de la creencia en que la historia puede actuar como maestra de la vida, en el sentido de enseñarles a los hombres cómo es que han llegado a donde están en la actualidad. Esa convicción, desterrada hace tiempo de la historiografía normalizada, actuó después de la crisis de 2001 como un desesperado salvavidas generador de sentido y de certezas en un momento especialmente complicado para la reproducción de las anteriores seguridades acerca de quiénes eran los argentinos. Pero seguramente la preocupación social por encontrar respuestas en el pasado, nacida de la angustia social generada durante la crisis, no habría bastado para sostener desde entonces ese fuerte interés por la historia. Fue clave el hecho de que se combinó con otros dos fenómenos con los que convergió: el Bicentenario y las políticas públicas. Como señaló Trímboli (2015, p. 225), esa reaparición de la historia "ocurre con la intervención muy activa del Estado". El bicentenario de la revolución de mayo de 1810 suscitó un gran número de producciones bibliográficas y audiovisuales, así como de celebraciones públicas, inauguración de obras y monumentos, en definitiva, un conjunto de políticas de memoria destinadas a celebrar los doscientos años de aquel episodio considerado seminal de la vida nacional. La celebración del Bicentenario fue, probablemente, la más relevante de las políticas de los gobiernos kirchneristas, para formular un nuevo sentido nacional e histórico, de un tono fuertemente fundacional, ligado a preceptos historiográficos provenientes del revisionismo histórico, especialmente en su versión izquierdista, que probablemente hoy constituyan el sentido común histórico de una porción significativa de la población nacional. En ese sentido también hay que ubicar al feriado permanente en recuerdo del combate de la Vuelta de Obligado de 1845 (en 2010) y el feriado extraordinario por la batalla de Tucumán de 1812 (en 2012). Se debe incluir asimismo la creación en 2011 del Instituto Nacional de Revisionismo Histórico Argentino e Iberoamericano Manuel Dorrego, dedicado a la reivindicación de quienes, según indica el decreto presidencial de su creación "defendieron el ideario nacional y popular ante el embate liberal y extranjerizante de quienes han sido, desde el principio de nuestra historia, sus adversarios" (PALERMO 2015, p. 189). Durante el festejo del Bicentenario un amplio conjunto de actividades públicas (culturales, educativas, mediáticas, intelectuales) invitaron a reflexionar sobre la particularidad de ser argentinos y de cuáles eran las tradiciones patrias. A riesgo de caer en el impresionismo, vale la pena mencionar que para el acto del 25 de mayo de 2004, en celebración de la fiesta patria, y también del primer año de gobierno de Néstor Kirchner, se convocó a la población a escuchar a 
destacados músicos en la Plaza de Mayo. Lo extraño no fue que se tocara en esa ocasión el himno nacional, sino que quien se encargara de hacerlo fuera Charly García -prohombre del rock argentino, ajeno a la solemnidad con la que suelen investirse estos actos- lo que marcó una recreación de los símbolos nacionales.

En el nuevo sentido de lo nacional que se intenta imprimir, la historia argentina aparece reverdecida como un elemento identitario de primer orden. De nuevo, con Trímboli (2015, p. 227) podría postularse que "la nueva presencia pública de la historia tiene la pretensión de reencontrar el sentido de nuestra experiencia a partir de la inmersión en el pasado". Reformulación y modernización de algunos museos nacionales (BOHOSLAVSKY et al. 2010a), propaganda, iniciativas públicas para crear espacios de recordación y erigir monumentos son algunas de esas políticas que tienden a instalar un sentido de orgullo nacional, entre cuyos patrimonios se incluye el tratamiento judicial de las violaciones a los derechos humanos sucedidas durante la última dictadura militar. En esa serie de actividades -numerosas, diversas, desplegadas por buena parte del país- participaron numerosos historiadores con credenciales académicas. Tanto en charlas como en guiones para dibujos animados, exhibiciones en centros de conservación de la memoria y en la elaboración de discursos que refirieran al pasado reciente, hubo involucrados destacados historiadores argentinos.

La auto-imagen de la Argentina que se promueve en muchos de los discursos públicos en los últimos años aparece revestida de una pertenencia inequívoca a América latina, lo cual es expresado en políticas de integración económica y comercial (como la continuidad del Mercosur y el lanzamiento de la UNASUR), pero también en muchas referencias simbólicas, centradas en el común nacimiento de las repúblicas americanas en las guerras de independencia de inicios del siglo XIX. Basta recordar que el cierre del mencionado acto del 2004 le cupo al cantautor cubano Silvio Rodríguez y que el show final de los festejos del Bicentenario contaron con la participación del también cubano Pablo Milanés y de la murga uruguaya Agarrate Catalina. En definitiva, el Bicentenario fue la oportunidad usada por el gobierno nacional para afirmar la inclusión de Argentina en América latina, en un esfuerzo de diferenciación con respecto a anteriores políticas de identidad que insistían en la pertenencia del país al primer mundo o a Occidente.

\section{Conclusiones}

Se aprecia que la historiografía académica se encuentra en una etapa de florecimiento, consolidación y expansión que se puede cuantificar con distintas variables (participantes en eventos, publicaciones especializadas, apertura de nuevas carreras de grado y posgrado, número de becarios e investigadores, proyectos en marcha, etc. ). Parece claro que esa "edad de oro" de la historiografía resulta áurea por el contraste con el cuarto de siglo anterior, en el que esa expansión estaba fuertemente amenazada por la estrechez presupuestaria y por la solidez de los patronazgos al interior de las instituciones universitarias y de promoción de la investigación. Sin embargo, el precio que se paga por desarrollar esa vigorosa tendencia de crecimiento, especialización y diversificación de la 
disciplina es la notoria dificultad para elaborar relatos (de distintos soportes) que puedan circular por espacios socialmente más amplios. En efecto, una de las consecuencias de la especialización disciplinaria es una percepción cada vez más aguda de la complejidad de los entramados sociales, de cuán abigarrados son los procesos de cambio y los actores, y en consecuencia, de lo enormemente dificultoso que resulta producir textos que respeten esa complejidad y a la vez puedan ser apropiados por un número de lectores más amplio que el ofrecido por las aulas universitarias. La paradoja que resulta de esa situación podría ser que en el momento en el que el Estado nacional coloca más fondos en la promoción del saber histórico científicamente fundado, los historiadores están en peores condiciones de intervenir con un macro-relato y una reconstrucción histórico-literaria global sobre el pasado argentino. Así, la condición que permite el éxito de la consolidación del campo normalizado sería, simultáneamente, la garantía de la inutilidad política de la historiografía. El triunfo del especialista implica abandonar al intelectual, para decirlo mal y pronto.

Sin embargo, esa conclusión debería ser revisada en función de un conjunto de prácticas que se vienen dando en la historiografía argentina en los últimos quince años. En efecto, numerosos historiadores profesionales, formados en la universidad normalizada de los años noventa, han desarrollado numerosas y muy originales iniciativas para dar a conocer su manera de interpretar el pasado nacional (reciente o no). En el despliegue de esas iniciativas han recurrido a soportes más originales y atractivos -como los audiovisuales o las colecciones para divulgación-, a espacios por fuera de la universidad -aulas de escuelas primarias, secundarias y penitenciarias, salas de museo, ex-centros clandestinos de detención, podcasts, etc.- y con ello han ido proponiendo una relación distinta con la disciplina histórica, las políticas públicas y la sociedad. La sensación paradójica y cruel de que los historiadores habían faltado a la cita con la historia en el 2001 fue un estímulo para participar de programas de radio, en la prensa masiva y en la elaboración de materiales bibliográficos y televisivos novedosos que, sin renunciar a la pretensión de tener niveles aceptables de cientificidad, esperaban encontrar un público receptor por fuera de los espacios académicos.

\section{Referencias bibliográficas}

ADAMOVSKY, Ezequiel. Historia, divulgación y valoración del pasado: acerca de ciertos prejuicios académicos que condenan a la historiografía al aislamiento. Nuevo Topo, n. 8, p. 91-106, 2011.

AGUILA, Gabriela; Luciano ALONSO (eds.). Procesos represivos y actitudes sociales. Entre la España franquista y las dictaduras del Cono Sud. Buenos Aires: Prometeo Libros, 2013.

ANDÚJAR, Andrea et al. Hilvanando historias. Mujeres y políticas en el pasado reciente latinoamericano. Buenos Aires: Instituto Interdisciplinario de estudios de Género (UBA) y Luxemburg Ediciones, 2011. 
BANDIERI, Susana. Historia de la Patagonia. Buenos Aires: Sudamericana, 2005.

BARRANCOS, Dora, Mujeres, entre la casa y la plaza. Buenos Aires: Sudamericana, 2008.

BERGERO, Adriana; REATI, Fernando (comps.). Memoria colectiva y políticas del olvido. Argentina y Uruguay, 1970-1990. Rosario: Beatriz Viterbo, 1997

BOHOSLAVSKY, Ernesto; DI LISCIA, María Silvia; GONZÁLEZ DE OLEAGA, Marisa. Del centenario al bicentenario. Memorias (y desmemorias) en el Museo Histórico Nacional. A contracorriente. Una revista de historia social y literatura de América Latina, v. 7, n. 3, p. 100-125, 2010a.

et al. (eds.). Problemas de historia reciente del Cono Sur. Buenos Aires: Universidad Nacional de General Sarmiento y Prometeo Libros, 2010b. 2 v.

BONASSO, Miguel. Recuerdo de la muerte. Buenos Aires: Planeta, 1984.

BRAGONI, Beatriz. San Martín. De soldado del rey a héroe de la nación. Buenos Aires: Sudamericana, 2010.

BUCHBINDER, Pablo. ¿Revolución en los claustros? La reforma universitaria de 1918. Buenos Aires: Sudamericana, 2008.

CARNOVALE, Vera, Federico LORENZ y Roberto PITTALUGA (comps.). Historia, memoria y fuentes orales. Buenos Aires: Memoria Abierta y CeDInCI, 2006.

CATTARUZZA, Alejandro. La Historia en tiempos difíciles. Revista Todavía, n. $2,2002$.

. Los usos del pasado. La historia y la política argentinas en discusión, 1910-1945. Buenos Aires: Sudamericana, 2007.

. Panel inaugural. In: CERNADAS, Jorge; LVOVICH, Daniel (comp.), Historia, ¿̇para qué? Revisitas a una vieja pregunta. Buenos Aires: Prometeo Libros y Universidad Nacional de General Sarmiento, 2010, p. 25-32.

. Las representaciones del pasado: historia y memoria. Boletín del Instituto de Historia Argentina y Americana Dr. Emilio Ravignani, n. 33, p. 155-164, 2011.

CHAMA, Mauricio. Peronización y radicalización de grupos de abogados en los años ' 60 y principios de los ' 70 . Cuestiones de Sociología. Revista de Estudios Sociales, n. 3, 2006, p. 143-168.

; SORGENTINI, Hernán. A propósito de la memoria del pasado reciente argentino. Notas sobre algunas tensiones en la conformación de un campo de estudios. Aletheia, v. 1, n. 1, 2010, p. 1-7. 
CHAVES PALACIOS, Julián (coord.). La larga memoria de la dictadura en Iberoamérica. Argentina, Chile y España. Buenos Aires: Prometeo libros, 2010.

CHIROLEU, Adriana; IAZETTA, Osvaldo. La política universitaria en la agenda de gobierno de Kirchner. In: MARQUINA, Mónica, SOPRANO, Germán y MAZZOLA, Carlos (coords.). Políticas, instituciones y protagonistas de la universidad argentina. Buenos Aires: Universidad Nacional de General Sarmiento, Universidad Nacional de San Luis y Prometeo Libros, 2009, p. 21-46.

DE AMÉZOLA, Gonzalo. Esquizohistoria. La Historia que se enseña en la escuela, la que preocupa a los historiadores y una renovación posible de la historia escolar. Buenos Aires: Libros del zorzal, 2008.

.Problemas y dilemas de la enseñanza de la historia reciente.

Entrepasados. Revista de Historia, n. 17, 2009, p. 137-162.

DE PRIVITELIO, Luciano et al. Historia de la Argentina contemporánea.

Desde la construcción del mercado, el Estado y la nación a nuestros días. Buenos Aires: Santillana, 1998.

DEVOTO, Fernando. Historia de la inmigración en la Argentina. Buenos Aires: Sudamericana, 2003.

DI MEGLIO, Gabriel. iMueran los salvajes unitarios! La Mazorca y la política en tiempos de Rosas. Buenos Aires: Sudamericana, 2007.

. Wolf, el lobo. Observaciones y propuestas sobre la relación entre producción académica y divulgación histórica. Nuevo Topo, n. 8, p. 107-120, 2011.

EUJANIAN, Alejandro. La memoria, los historiadores y el pasado. Boletín del Instituto de Historia Argentina y Americana Dr. Emilio Ravignani, n. 33, p. 175-180, 2011.

FIELD, Sean. De hijastra a anciana: ¿Se ha vuelto "respetable" la historia oral? International Oral History Association Debate, 2009. Disponible en: http://www.iohanet.org/debate/?p=21. Accedido el 29 jun. 2015.

FRADKIN, Raúl. ¿Y el pueblo dónde está? Contribuciones para una historia popular de la revolución de independencia en el Río de la Plata. Buenos Aires: Prometeo Libros, 2008.

FRANCO, Marina. El exilio. Argentinos en Francia durante la dictadura. Buenos Aires: Siglo Veintiuno Editores, 2008.

. La "teoría de los dos demonios" en la primera etapa de la posdictadura. In: FELD, Claudia; FRANCO, Marina (eds.). Democracia, Hora Cero. Actores, políticas y debates en los inicios de la posdictadura. Buenos Aires: Fondo de Cultura Económica, 2015, p. 23-80.

; LEVÍN, Florencia (eds.). Historia reciente. Perspectivas y desafíos para un campo en construcción. Buenos Aires: Paidós, 2007. 
GIORDANO, Verónica. La resistencia simbólica en las haciendas de la sierra sur peruana. Estudios Sociales, n. 11, 1996, p. 161-177.

GOLDMAN, Noemí. iEI pueblo quiere saber de qué se trata! Historia oculta de la Revolución de Mayo. Buenos Aires: Sudamericana, 2009.

GONZÁLEZ, María Paula. La historia reciente en la escuela. Saberes y prácticas docentes en torno a la última dictadura. Los Polvorines: Universidad Nacional de General Sarmiento, 2014.

GROPPO, Bruno y FLIER, Patricia (eds.) La imposibilidad del olvido. Recorridos de la memoria en Argentina, Chile y Uruguay. La Plata: Ediciones al Margen, 2001.

GUHA, Ranajit. Las voces de la historia y otros estudios subalternos. Barcelona: Crítica, 2002.

HORA, Roy y TRÍMBOLI, Javier. Pensar la Argentina. Los historiadores hablan de historia política. Buenos Aires: El cielo por asalto, 1994.

HUYSSEN, Andreas. En busca del futuro perdido. Cultura y memoria en tiempos de globalización. México: FCE, 2002.

JELIN, Elizabeth; KAUFMAN, Susana (eds.). Subjetividad y figuras de la memoria. Madrid y Buenos Aires: Siglo XXI de España Editores y Siglo XXI Editora Iberoamericana, 2006.

118 ; $\quad$ memoria. Madrid: Siglo XXI Editores de España y Siglo XXI de Argentina Editores, 2005.

JENSEN, Silvina. Los exiliados. La lucha por los derechos humanos durante la dictadura militar; Buenos Aires: Sudamericana, 2010.

KESSLER, Gabriel; SVAMPA, Maristella; GONZÁLEZ BOMBAL, Inés (coords.). Reconfiguraciones del mundo popular. El conurbano bonaerense en la post-convertibilidad. Buenos Aires: Prometeo Libros y Universidad Nacional de General Sarmiento, 2010.

KINDGARD, Adriana. Tradición y conflicto social en los Andes argentinos. En torno al Malón de la Paz de 1946. Estudios Interdisciplinarios de América Latina y el Caribe, v. 15, n. 1, p. 165-184, 2004.

LANATA, Jorge. Argentinos. Barcelona: Ediciones B, 2002.

ADN. Mapa genético de los defectos argentinos. Buenos Aires: Planeta, 2004.

LVOVICH, Daniel. Burócratas, amigos, ideólogos y vecinalistas: el reclutamiento de funcionarios municipales de Morón durante la dictadura militar (19761983). In: BOHOSLAVSKY, Ernesto; SOPRANO, Germán (eds.). Un Estado con rostro humano. Buenos Aires: Universidad Nacional de General Sarmiento, 2010, p. 411-430. 
MALERBA, Jurandir. La historia en América Latina. Ensayo de crítica historiográfica. Rosario: Prohistoria Ediciones, 2010.

- Acadêmicos na berlinda ou como cada um escreve a História? uma reflexão sobre o embate entre historiadores acadêmicos e não acadêmicos no Brasil à luz dos debates sobre Public History. História da Historiografia, n. 15, p. 27-50, 2014.

MARQUINA, Mónica. ¿Hay una política universitaria K? Posibles respuestas a partir del análisis del financiamiento. In: CHIROLEU, Adriana et al. (eds.).

La política universitaria de los gobiernos Kirchner: continuidades, rupturas, complejidades. Buenos Aires: Universidad Nacional de General Sarmiento, 2012, p. 75-92.

MASTROGREGORI, Massimo. Google, la bibliografia e l'attenzione. Le parole e le cose. Disponible en: http://www.leparoleelecose.it/?p=4357. Accedido el 8 jun. 2016

MAYO, Carlos. Patricio de Belén: Nada menos que un capataz. The Hispanic American Historical Review, v. 77, n. 4, p. 597-617, 1997.

MORENO, José Luis. Éramos tan pobres... De la caridad colonial a la Fundación Eva Perón. Buenos Aires: Sudamericana, 2009.

PAGANO, Nora. La producción historiográfica reciente: continuidades, innovaciones, diagnósticos. In: DEVOTO, Fernando (dir.). Historiadores, ensayistas y gran público: la historiografía argentina, 1990-2010. Buenos Aires: Biblos, 2010, p. 39-67.

PALERMO, Vicente. La alegría y la pasión. Relatos brasileños y argentinos en perspectiva comparada. Buenos Aires: Katz editores, 2015.

PIGNA, Felipe. Los mitos de la historia argentina 1. De los pueblos originarios y el descubrimiento de América a la independencia. Buenos Aires: Grupo Editorial Norma-Planeta, 2004.

. Los mitos de la historia argentina 2. De San Martín a 'el granero del mundo'. Buenos Aires: Planeta, 2005.

. Los mitos de la historia argentina 3. Desde la ley Sáenz Peña a los albores del peronismo. Buenos Aires: Planeta, 2006.

. Los mitos de la historia argentina 4. La Argentina peronista (19431955). Buenos Aires: Planeta, 2008.

RIVERA CUSICANQUI, Silvia; BARRAGÁN Rossana (eds.). Debates post coloniales: una introducción a los estudios de la subalternidad. La Paz: Historias-Sephis-Aruwiri, 1997.

RODRÍGUEZ, Martha. Una década de historiografía argentina (1990-2000). Orientaciones, temas y problemas. Anuario del Centro de Estudios Históricos 'Prof. Carlos S. A. Segreti', año 2, n. 3, p. 285-303, 2002/2003. 
. Los relatos exitosos sobre el pasado y su controversia. Ensayistas, historiadores y gran público, 2001-2006. In: DEVOTO, Fernando (dir.). Historiadores, ensayistas y gran público: la historiografía argentina, 1990-2010. Buenos Aires: Biblos, 2010, p. 117-137.

SALVATORE, Ricardo. Wandering paysanos. State order and subaltern experience in Buenos Aires during the Rosas era. Durham: Duke University Press, 2003.

SEMÁN, Pablo, MERENSON, Silvina y NOEL, Gabriel. Historia de masas, política y educación en Argentina. Clío \& Asociados. La Historia Enseñada, n. 13, p. 69-93, 2009.

SVAMPA, Maristella y PEREYRA, Sebastián. Entre la ruta y el barrio. La experiencia de las organizaciones piqueteras. Buenos Aires: Biblos, 2009.

TRÍMBOLI, Javier. La vuelta de la historia. Consideraciones sobre la nueva presencia pública de la historia. Pasado Abierto, n. 1, p. 220-229, 2015.

TRÍMBOLI, Javier et al. Manifiesto de octubre. Para una crítica de la razón académica. Buenos Aires, 1997. Disponible en: http://ezequieladamovsky. blogspot.com.ar/2013/03/normal-0-manifiestode-octubre-para-una. html. Accedido el 11 dic. 2015.

VARELA, Gladys. VII Jornadas Interescuelas de Historia. Revista de Historia, n. 8, , p. 257-258, 2000.

120 VELIZ, Romina et al. En boca de todos: apuntes para divulgar historia. Interface - a journal for and about social movements, v. 2, n. 1, p. 334-380, 2010. 